\title{
The Effect of Life Cycle Cost Information on Consumer Investment Decisions Regarding Eco-Innovation
}

Josef Kaenzig and Rolf Wüstenhagen

\section{Keywords:}

behavioral economics consumer behavior industrial ecology life cycle costing (LCC) sustainable consumption sustainability marketing
Address correspondence to Josef Kaenzig

Institute for Economy and the Environment Tigerbergstrasse 2 9000 St.Gallen

Switzerland

jkaenzig@postmail.ch

www.iwoe.unisg.ch

(c) 2009 by Yale University

DOI: $10.1111 / j .1530-9290.2009 .00195 . x$

Volume 00 , Number 0
I

\begin{abstract}
Summary
Life cycle cost (LCC) computations are a well-established instrument for the evaluation of intertemporal choices in organizations, but they have not been widely adopted by private consumers yet. Consumer investment decisions for products and services with higher initial costs and lower operating costs are potentially subject to numerous cognitive biases, such as present-biased preferences or framing effects. This article suggests a classification for categorizing different cost profiles for eco-innovation and a conceptual model for the influence of LCC information on consumer decisions regarding eco-innovation. It derives hypotheses on the decision-making process for eco-innovation from a theoretical perspective. To verify the hypotheses, the publication reviews empirical studies evaluating the effects of LCC information on consumer investment decisions. It can be concluded that rather than finding ways to make customers pay more for environmentally sound products, the marketing challenge for eco-innovation should be reconceptualized as one of lowering customers' perceived initial cost and increasing awareness of LCC. Most existing studies report a positive effect of LCC information on the purchase likelihood of eco-innovations. Disclosing LCC information provides an important base for long-term thinking on the individual, corporate, and policy levels.
\end{abstract}




\section{Introduction}

Global sustainability challenges, such as climate change and the depletion of natural resources, indicate the need for innovation. Although significant technological development has taken place in the energy sector and energy prices rise and are highly volatile, the market diffusion of environmentally sound innovations (eco-innovation) has remained at surprisingly low levels so far. Higher initial costs are one of the major barriers for eco-innovation (Kempton et al. 1992; Jaffe and Stavins 1994; Kaenzig and Wüstenhagen 2008). Disclosure of operating costs was suggested more than 30 years ago as a means to overcome this barrier (Lund 1978), but only a few authors have empirically tested the effect of explicit operating cost information on investment decisions. Another important barrier to the diffusion of eco-innovation is the existence of external costs and benefits and information asymmetries. The marketing literature has suggested internalization of public benefits as a way to accelerate market diffusion of green products and has identified segments of customers who are willing to pay more for these products (Villiger et al. 2000; Kleinhückelkotten 2005; Kirchgeorg and Greven 2008). Recent literature on energy-efficient products and carbon reduction potentials (Enkvist et al. 2007), however, indicates that the traditional "green and expensive" versus "brown and cheap" dichotomy may be an oversimplification. This article suggests breaking down the relative costs of eco-innovations into two dimensions, namely initial costs and operating costs. When one does so, it becomes evident that a wide range of environmentally sound products are characterized not simply by higher total cost but rather by a different investment profile, namely higher initial cost versus lower operating cost. Using an example from the residential energy sector, figure 1 provides a schematic illustration of the cumulative costs of a product with a high purchase price and low operating costs (A) and a conventional product with a lower purchase price and higher operating costs (B).

As can be seen from figure 1, the cumulative life cycle costs (LCC) for eco-innovations may be even lower than for conventional alternatives, but the decision maker will only realize

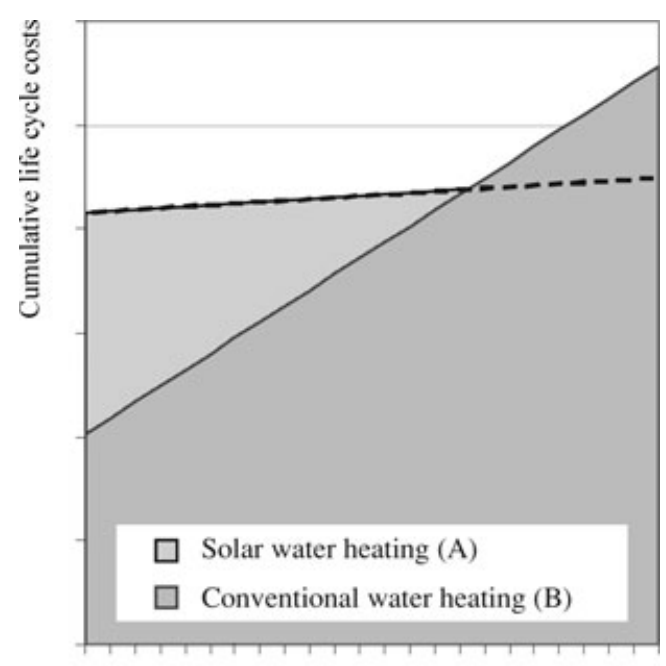

Lifetime of the products (years)

Figure I Cumulative life cycle costs illustrated by a comparison of a solar hot water system and a conventional system.

this if he or she considers the cumulative LCC over the full lifetime of the product. If, conversely, the consumer takes only initial costs into account, he or she may choose a conventional product with both inferior environmental performance and higher LCC. This observation has important implications for understanding consumer decisions regarding eco-innovation and hence for sustainability marketing and for the design of policy measures.

Drawing on Rennings's (2000) theoretical contribution on eco-innovations, the concept of eco-innovation covers consumption patterns of new products and services that have a lower environmental impact than their more popular counterparts. As many environmental impacts are linked to the consumption of nonrenewable energies, a very important category of eco-innovation is energy-efficient products and services. Examples include solar thermal water heating, energy-efficient appliances, lowenergy windows, energy-efficient and hybrid cars, energy-efficiency consulting services, car-sharing services, and water-saving shower heads (Tukker and Jansen 2006; Bilharz 2007; Kaenzig and Jolliet 2007). 
Important decisions regarding eco-innovation in the residential sector are made rather infrequently yet result in relatively large expenses for products that determine the amount and type of energy consumed during their 10-30-year lifetime. These consumer investment decisions regarding eco-innovations are characterized by

- different investment profiles over timethat is, often higher initial cost (purchase price and set-up cost) and lower operating cost (maintenance and running cost);

- information asymmetries due to search, experience, and credence attributes (Nelson 1970; Darby and Karni 1973) of ecoinnovations;

- externalities (e.g., environmentally sound alternatives imply a higher collective benefit but lower or equal private benefits than conventional alternatives; Kaas 1992; Rennings 2000); and

- infrequent decisions that require the consumer to engage in an extensive decisionmaking process (Blackwell et al. 2005; Esch et al. 2007), which implies high involvement, high cognitive effort, and a substantial need for information due to limited experience.

Kempton and colleagues (1992) found that, in general, it is easier to achieve one-time changes in behavior than to alter and maintain repetitive behavior changes. That is another reason to pay particular attention to cognitively demanding decision-making processes for strategic choices for sustainable consumption, as suggested by this article.

The overarching objective of this research is to increase the understanding of consumer investment decisions regarding eco-innovations with lower operating costs than other competing products. This is important, because lower operating costs and higher initial costs are characteristics of many eco-innovations. With respect to the four characteristics mentioned above, the aim of this article is to conceptualize and provide an overview on the signaling effect of different types of LCC information to overcome information asymmetries. LCC information denotes any information about total or operating costs and also total or operating savings. The most obvious form is the information on total or operating costs in monetary units (explicit LCC information), but eco-labels, such as the European Union (EU) energy efficiency label, also transmit LCC information to the consumer (implicit LCC information), because higher energy efficiency in the use phase of a product is directly linked to lower operating cost. To achieve a better understanding of specific aspects of such consumer investment decision processes, in this article we adopt a theoretical behavioral perspective and then verify hypotheses arising from theory by analyzing empirical research on the effect of LCC information.

The article aims to answer the following research questions:

1. How does communication regarding LCC (rather than merely initial costs) influence the purchase likelihood of eco-innovations with higher initial costs yet lower operating costs?

2. Which type and temporal framing of LCC information have the strongest effect on the purchase likelihood of ecoinnovations?

3. Which consumer segments can be influenced by LCC information?

The following section reviews the relevant theoretical literature and derives a series of hypotheses. The next section presents a classification of eco-innovations according to their relative initial and operating costs and introduces a conceptual model of the influence of LCC information on consumer investment decisions regarding eco-innovation, which is grounded in the previous section on theory development. The hypotheses are then compared with the existing empirical studies on the effect of LCC information. The concluding section answers the abovementioned research questions and specifies implications for further research as well as for policy and marketing.

\section{Theoretical Background and Development of Hypotheses}

There are different disciplinary approaches to individual decision making for eco-innovation 
and proenvironmental behavior. Five research traditions address decision models: microeconomics, behavioral economics, technology diffusion, social psychology, and sociology. All of these disciplines contribute to the understanding of decision-making behavior through a considerable number of empirical studies on new energy technologies. For the investigation of cost information effects, economic approaches serve best. Only few empirical studies on eco-innovations are based on behavioral economics, and of those that are, most deal with implied discount rates in consumer durable purchasing (Wilson and Dowlatabadi 2007).

The following subsection of this article derives hypotheses from behavioral economics and microeconomics. It provides an overview of the potential role of LCC information in overcoming information asymmetries, the role of LCC information and cognitive biases in investment decisions determining resource and energy use, the special character of intertemporal choices and their implications for resource and energy consumption, and the heterogeneity among customers for eco-innovation.

\section{LCC Information to Overcome Information Asymmetries}

Drawing on institutional economics, authors such as Kaas (1992) have discussed information asymmetries that are prevalent in markets for environmentally sound products and their implications for marketing. Consumers are interested in goods as a bundle of different product attributes (Lancaster 1966) that can be categorized as search, experience, and credence attributes. Search attributes can be identified by consumers prior to purchase (e.g., price, color, size), whereas experience attributes can only be determined after purchase (Nelson 1970). Finally, credence attributes cannot be checked before or after purchase (Darby and Karni 1973). Knowledge about these product attributes is asymmetrically allocated between buyers and sellers. As documented in the seminal work by Nobel Prize laureate Akerlof (1970) on the "market for lemons," such information asymmetries can lead to market failure in the form of a crowding out of high-quality products.
Efforts to provide consumers with information about product characteristics that constitute search, experience, or credence attributes are termed signaling (Spence 1973), whereas the activity of consumers to research and check out these characteristics of a product is called screening (Stiglitz 1975). Information asymmetry can be overcome in different ways. Markets for products with search attributes are able to produce this information relatively easily, whereas goods with credence attributes need a reputable information source that consumers can rely on. This information can, for example, be provided in the form of brands or explicit or implicit LCC information (i.e., eco-labels). Brands and eco-labels fulfill two main functions for consumers: They inform consumers about intangible product characteristics (information function, e.g., quality), and they may provide a value in themselves (value function, e.g., prestige). An eco-label transforms the credence attribute environmental performance into a search attribute by third-party certification, which guides consumers' investment decisions (Sammer and Wüstenhagen 2006). This article investigates whether explicit LCC information fulfills a similar function and also whether the type of LCC information influences the purchase likelihood of eco-innovations. To begin, we set forth the following two hypotheses:

Hypothesis 1a: Certified LCC information is used as a search attribute for eco-innovations with lower operating costs than competing products.

Hypothesis $1 b$ : The type (i.e., cost only, cost savings, energy-efficiency label) of LCC information influences the purchase likelihood of eco-innovations with lower operating costs than competing products.

\section{LCC Information and Cognitive Biases in Investment Decisions}

Decision-making models that assume a homo oeconomicus have been criticized by other disciplines for the assumptions that markets are efficient, that decision makers behave rationally, and that consumers are perfectly informed and have fixed preferences. Behavioral economics attempts to close gaps of the traditional 
microeconomic decision-making models by integrating psychological aspects into decision making. A range of common heuristics, or simple decision rules, are evidenced that violate assumptions of conventional microeconomic theory about consumer choice, such as availability (heuristics) and framing effects (Tversky and Kahneman 1974), anchoring and adjustment, and status quo biases (Samuelson and Zeckhauser 1988). The energy efficiency gap (Jaffe and Stavins 1994), which illustrates the fact that economic agents often do not adopt energy-efficient technology even if it lowers their total LCC, can be partially explained by the status quo bias, which points to preferences toward alternatives that maintain or perpetuate the current situation even when better alternatives exist. In summary, a significant effect of cognitive biases is that they lead to conservatism in people's adjustment to new information (Tversky and Kahneman 1974; Kahneman 2003) and constitute, therefore, a frequent barrier for eco-innovation (Jackson 2005).

Prospect theory (Kahneman and Tversky 1979) and theories on mental accounting stipulate that the reference points for comparison also have a strong influence on consumer choices (Thaler 1980; Loewenstein and Prelec 1992). Referencing of alternatives (Tversky and Kahneman 1981) is a major driver of investment decisions. Individuals "code" the outcomes of various prospects and alternatives as either gains or losses relative to some reference point. This reference point for eco-innovation can be a wellestablished conventional product or service.

The idea to use comparative LCC information to influence decision makers is not new; it is quite well established for the evaluation of intertemporal choices in organizations. It has been discussed in several research disciplines, such as general management (Dyllick et al. 1997) as well as engineering and property management (Rebitzer 2005; Hunkeler et al. 2008). The discussion on comparative LCC disclosure to influence consumer decisions is not new either but is less advanced. The empirical evidence for the effect of comparative LCC disclosure and its framing on consumer investment decisions has not been reviewed yet. One can hypothesize that the disclosure of LCC lowers the perceived costs of ecoinnovations in comparison to the perceived costs of conventional counterparts with higher operating costs. The resulting working hypothesis on the effect of LCC is as follows:

Hypothesis 2: The purchase likelihood of products with higher initial and lower operating costs increases when LCC comparisons are provided.

\section{Intertemporal Choices, Framing Effects, and Eco-Innovation}

Eco-innovations often imply higher purchase prices and lower operating costs, and their purchase likelihood is therefore negatively correlated to high implicit discount rates. Many contributions in the context of residential energy investments discuss intertemporal choice and determine implied discount rates. In a review on time discounting, Frederick and colleagues (2002) report that individuals use different discount rates for different types of goods in different contexts (see also the work by Lynch and Wood 2006). Revealed discount rates for energy-efficient technologies were found in the $5 \%$ to $100 \%$ range, and higher rates were applied to refrigerators and water heaters than to space heating equipment and measures to improve the thermal integrity of buildings (Train 1985). This finding implies that consumers accepted at the time of the survey that the relative payback period (in comparison to the total lifespan) of heating systems is longer than the relative payback period for refrigerators. The high observed variability suggests that implied discount rates are influenced by different elements of the decision context, such as the perceived risk, framing effects, available time, involvement, and social context (income, level of knowledge, etc.). This article focuses on costs and the influence of the temporal framing of LCC information on intertemporal choices.

Thaler (1981) reports on hyperbolic discounting behavior, which explains the tendency for people to have a stronger preference for more immediate payoffs relative to later payoffs. This tendency is also called present-biased preferences, and it increases when payoffs are close to the present. From behavioral pricing research, one can learn that paying a bill in small portions ("pennies a day") is often more attractive than 
paying the whole sum at once (Gourville 1998). One can hypothesize that aggregate operating cost disclosures have a higher effect on the purchase likelihood of eco-innovations than information on annual operating costs because the amounts are less impressive. The resulting hypothesis on the temporal framing of LCC is as follows:

Hypothesis 3: The temporal framing of LCC information influences the implied discount rates for consumer investment decisions and thereby the purchase likelihood of ecoinnovations.

\section{Heterogeneity Among Customers for Eco-Innovations}

Strategic sustainability marketing distinguishes three main consumer segments that were elaborated and refined over the last decade (Meffert and Bruhn 1996; Villiger et al. 2000; Wüstenhagen et al. 2001; Belz 2006; Kaenzig and Wüstenhagen 2008): The first consumer segment consists of dark-green consumers (environmentally active consumers), the second of light-green consumers (who can be motivated to become environmentally active), and the third segment is not interested in the environmental aspects of products. Environmental advantages appeal differently to the three consumer segments. The willingness to pay more for environmental advantages of eco-innovations is significant for darkgreen consumers. As they represent a rather small segment in most countries, growth-oriented companies have to target light-green consumers beyond the eco-niche (Villiger et al. 2000). These light-green consumers also consider the environmental superiority of products and services as an added value, and their latent willingness to pay can be activated by different stimuli that illustrate the advantages of eco-innovations. If companies and policy makers manage to combine the environmental dimension with classical buying criteria, such as convenience, performance, functionality, design, and durability, these consumer groups are open for eco-innovations. To reach environmentally inactive consumers, Belz (2006) suggests, companies and policy makers should present the social and environmental advantages of a product as free added value. Given this frame- work for strategic sustainability marketing, the following hypothesis can be set up:

Hypothesis 4a: Sensitivity to information on initial costs of eco-innovation decreases from mainstream to light-green and dark-green consumers.

Hypothesis $4 b$ : Sensitivity to information on operating costs of eco-innovation decreases from mainstream to light-green and darkgreen consumers.

Hypothesis $4 \mathrm{~b}$ implies that the effect of LCC information is also dependent on the consumer segment.

\section{Conceptual Model: LCC of Eco-Innovations and Cost Cognition}

Most marketing efforts for eco-innovation implicitly assume that environmentally sound consumption patterns are more expensive. This article suggests a new approach distinguishing four different categories of eco-innovation on the basis of their initial and operating cost relative to conventional counterparts (see figure 2). If we take into account insights from behavioral economics about referencing of alternatives, the classification of eco-innovations is dependent on costs of conventional counterparts (reference products), which consumers use to evaluate costs. Looking at operating costs as a second cost dimension is a promising prospect to promote ecoinnovations. "No brainers" are easy-selling items whose initial and operating costs are both lower than those of competing products and services. It can be assumed that their diffusion takes place without special marketing efforts or policy intervention. Products that fall under the category of lower initial costs and higher operating costs' are easier to market than products with higher initial costs. The present research does not focus on "tough sell" eco-innovations, which cause higher initial and higher operating costs than conventional counterparts; this research puts emphasis on the upper left quadrant, products with higher initial and lower operating costs. There are numerous examples of eco-innovation in this category, all products contained within the energy efficiency gap (Jaffe and Stavins 1994), for 
Figure 2 Classification of products according to initial, operating, and total life cycle costs.

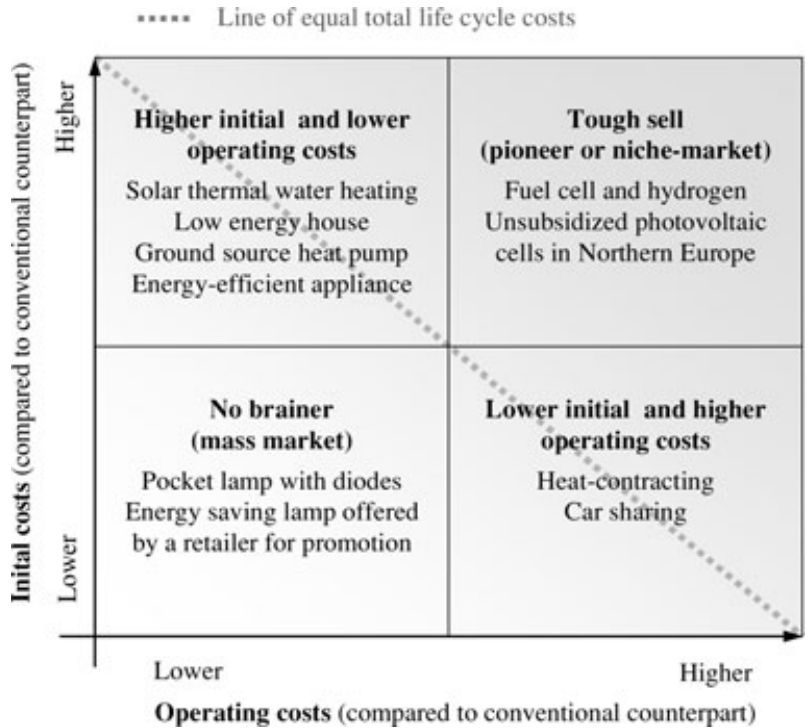

Operating costs (compared to conventional counterpart) instance. Their wider diffusion could enable important energy savings, which result in environmental gains and lower operating costs compared to conventional alternatives (Kaenzig and Jolliet 2007; Bilharz 2007).

For eco-innovations in the upper left quadrant and the lower right quadrant, two different subcategories can be distinguished: eco-innovations with higher total LCC than conventional counterparts, and eco-innovations with lower total LCC than conventional counterparts. The diagonal is the line of products and services with equal total LCC but different allocations of initial and operating costs. Eco-innovations that are more expensive than their conventional counterparts are located above the diagonal; the ones that are less expensive are below.

Two strategies to overcome the energy efficiency gap (upper left quadrant) and higher initial costs of eco-innovations can be outlined:

1. bringing down real initial costs and moving from the upper left to the lower left quadrant (e.g., economies of scale, subsidy program), and

2. shifting initial costs to operating costs and moving toward the lower right quadrant (e.g., leasing, renting instead of selling).

Examples for the first strategy are a less expensive car with hybrid engine technology and electricity production with photovoltaics in lowlatitude regions without electricity grids. Examples for the second strategy are heat contracting with environmentally sound heating technologies and renewable energy sources and carsharing, which has high operating (variable) costs and low initial (fixed) costs.

How does LCC information influence the decision of consumers to buy these different types of eco-innovation? Figure 3 presents the conceptual model and hypothesized causal relationships that were derived from the theoretical discussion in the previous section of this article on theory development. The model suggests that information on initial cost and LCC influences the likelihood that consumers will buy the category of eco-innovation that this article is focusing on, with its higher initial and lower operating cost. This relationship is mediated by perception of initial costs and LCC. The relationship between information on LCC and perceived LCC, in turn, is moderated by the type of LCC information, the temporal framing of LCC information, and the consumer-specific sensitivity to LCC. Analogously, the relationship between information on initial cost and perceived initial cost is moderated by consumer-specific sensitivity to initial cost. Finally, the relationship between perceived initial cost and LCC, on the one hand, and the purchasing decision, on the other, is moderated by 


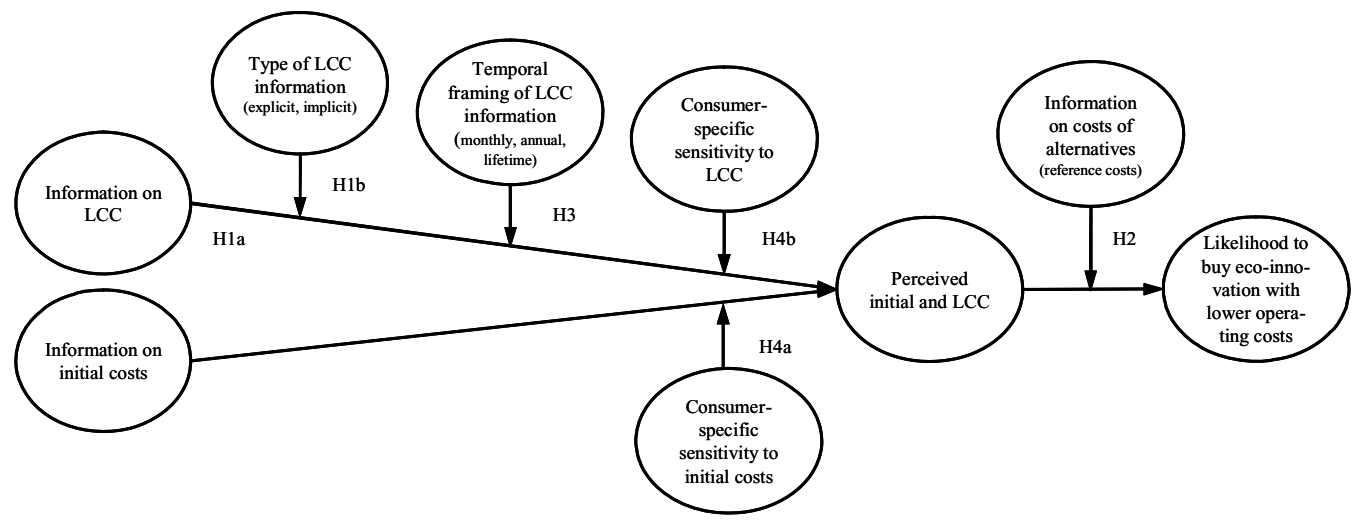

Figure 3 Conceptual model of the influence of life cycle cost (LCC) information on consumer investment decisions regarding eco-innovation.

comparative LCC information that can be used as reference point.

\section{Analysis of Empirical Evidence on the Effect of LCC Information}

This section compares the hypotheses arising from the theoretical literature with existing empirical evidence. There is little appropriate reallife evidence measuring and reporting the effect of LCC disclosure on consumer decisions regarding eco-innovations. At first glance, it seems preferable to use revealed preferences (market data) to determine the importance of product attributes whenever possible. In a considerable number of situations, however, it is not possible or appropriate to use revealed preferences (Louviere et al. 2000). The most obvious case in which it is not possible to use revealed preferences is for new products or product features for which no market data are available. In the case of residential energy supply, for instance, LCC information is very rarely disclosed. Therefore, in this article we review a number of surveys based on stated preferences (e.g., choice experiments) to determine indirectly the effect of LCC information on consumer decision-making.

Table 1 lists studies that provide empirical evidence on the effect of different types of LCC information on consumer investment decisions regarding eco-innovations. The last column indicates whether the study corroborates the six hypotheses. It shows, for instance, that all of the reviewed studies indicate a positive influence of comparative LCC information on the purchase likelihood of eco-innovation and corroborate Hypothesis 2. One can also notice that this effect is stable for different countries. In countries where homeowners tend to resell their houses more often, the effect of LCC information on long-term investment behavior might be smaller. It can be deduced from the work of Diekmann and Meyer (2007) and Liebermann and Ungar (2002) that the effect of LCC information depends on various socioeconomic characteristics, such as income, and also on consumers' level of knowledge about energy efficiency. The following paragraphs provide a short description and discussion of the studies figured in table 1 . Recent studies as well as studies that contain information on several hypotheses are discussed in more detail than studies that provide insights on only one or two of the hypotheses in the present article.

Early research by McNeill and Wilkie (1979) investigated women's design preferences for refrigerators. They found that the availability of energy use information led to a nonsignificant decrease in energy use of $2.3 \%$. The type of energy use information (kilowatt-hours per year $[\mathrm{kWh} / \mathrm{yr}]$ and dollars per year) did not reveal statistically significant differences between treatment groups.

With a very similar experimental setting, Hutton and Wilkie (1980) found a very positive 


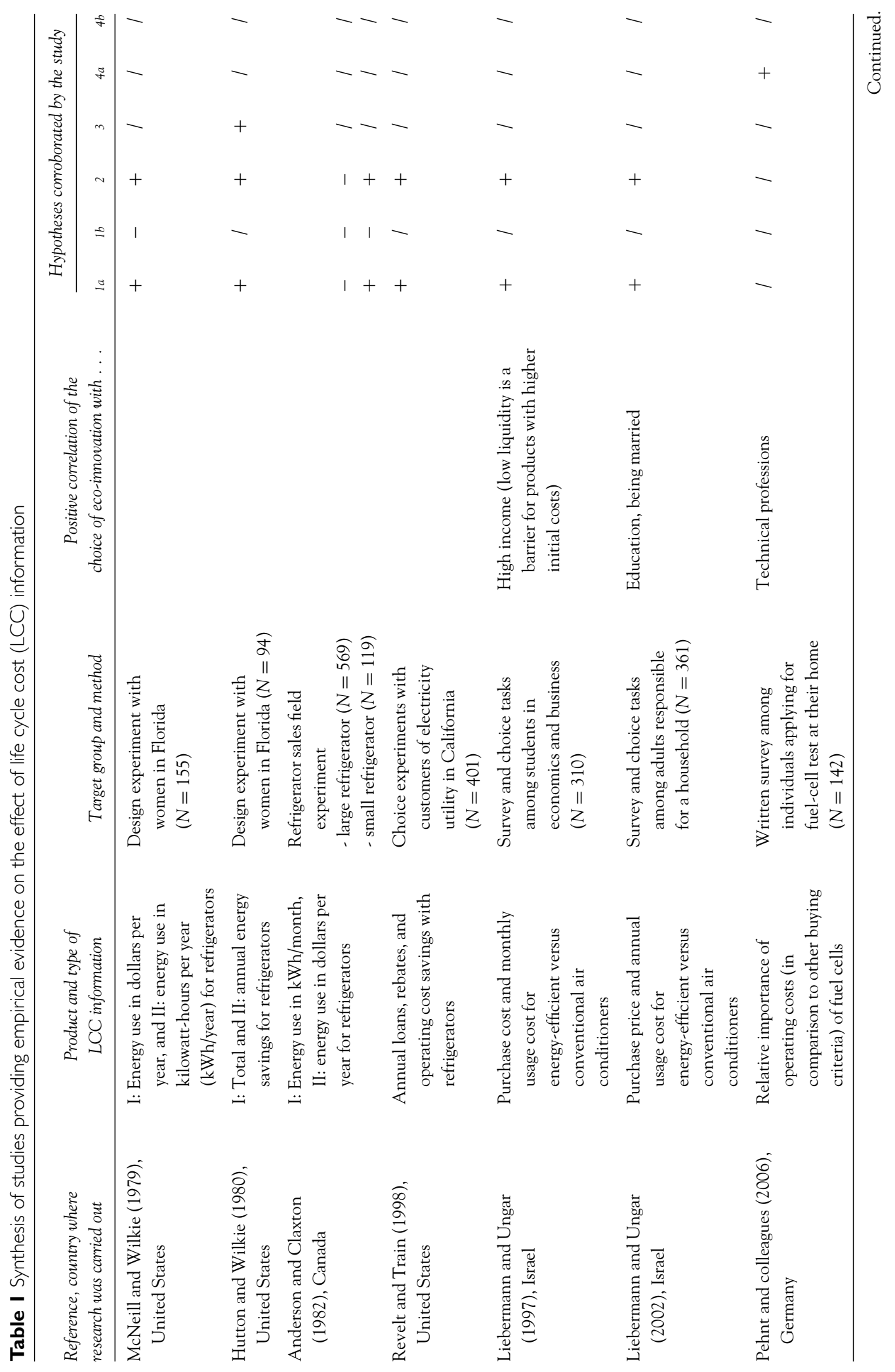




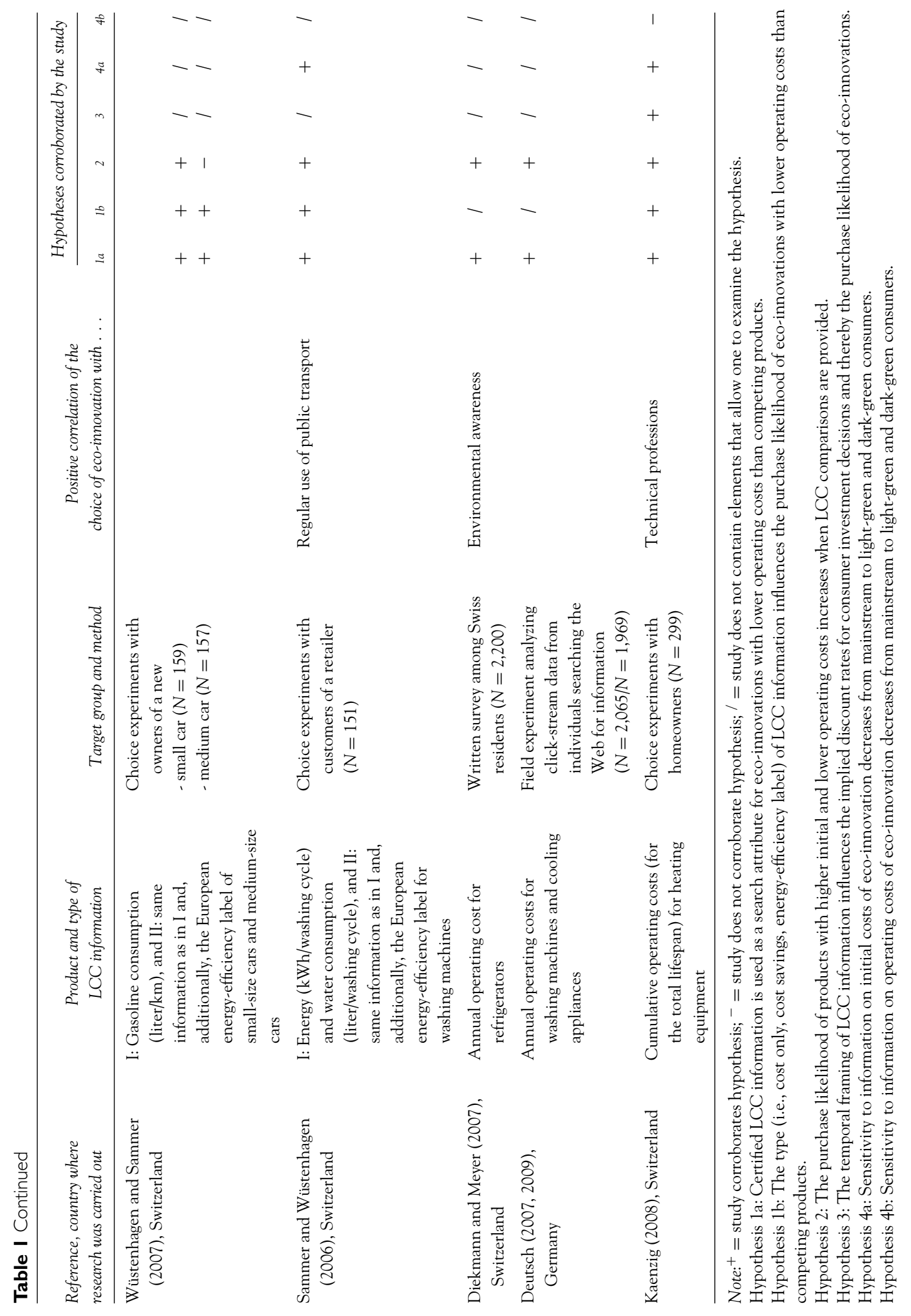


effect of cumulative lifetime operating cost information on the choice of energy-efficient refrigerators. The effect of annual cost information was clearly smaller. This is not surprising when one considers findings from behavioral research about temporal framing effects.

Anderson and Claxton (1982) conducted a refrigerator sales field experiment on LCC information. Refrigerators carried a kind of energy label disclosing either kilowatt-hours per month or dollars per year. The availability of energy use information reduced mean energy use by $12 \%$ for small refrigerators, although for large refrigerators the effect was not significant. Differences between the effects of monetary LCC information and the effects of physical information were statistically insignificant.

Liebermann and Ungar (1997 and 2002) carried out two similar surveys. These surveys consisted of a simple choice task in which respondents had to choose between two models of air conditioners. The survey, distributed among business students (Liebermann and Ungar 1997), showed that monthly operating cost disclosure (implying a 4\% total cost advantage over a lifespan of 10 years) convinced about 38\% of the students to opt for the energy-efficient air conditioner. Some years later, Liebermann and Ungar (2002) did a similar survey disclosing yearly operating cost (with a $9 \%$ total cost advantage). Roughly $75 \%$ of adults running a household opted for the energy-efficient model.

Revelt and Train (1998) used data from an electricity utility in California to analyze the refrigerator preferences of 401 customers. They tested the effect of loans and rebates for energyefficient refrigerators. Revelt and Train (1998) also disclosed operating cost savings and found that their influence on purchase decisions was significant.

Comparative information on energy efficiency can be seen as a proxy for operating costs. Energyefficiency labels are therefore an interesting case for understanding the effect of LCC signaling. The European Energy Label scheme is a prominent policy measure to communicate energy consumption for appliances and cars to consumers. The different levels of the energy-efficiency rating relate to the energy consumption of appliances and cars in the use stage. Choice exper- iments have shown that the energy-efficiency rating influences the purchase likelihood of environmentally sound household appliances (Sammer and Wüstenhagen 2006). Such experiments also show that the effect of energy-efficiency rating is greater than the effect of information on resource consumption per washing cycle. This evidence supports Hypothesis $1 \mathrm{~b}$, which stipulates that the type of LCC information influences the purchase likelihood of eco-innovations. Therefore, one can state that one has to distinguish products that are subject to existing energyefficiency ratings from those that are not when planning to use costs for signaling. Hypothesis 3-which assumes that the implicit discount rate can be influenced by LCC information-is also supported by the study from Sammer and Wüstenhagen (2006).

The influence of the European energyefficiency rating on car choices (Wüstenhagen and Sammer 2007) was much smaller than for household appliances (Sammer and Wüstenhagen 2006), although the design of both surveys was very similar. Different explanations are plausible. First, the European labeling system is more complex for cars than for household appliances, because it distinguishes different car sizes; second, the decision-making processes are not the same for cars and household appliances; and, third, energy consumption is more important for household appliances because the share of energy costs in total LCC is higher for household appliances than for cars.

The analysis of choice experiments described by Sammer and Wüstenhagen (2006) also supports Hypothesis 4a. The sensitivity to information on initial costs of eco-innovation decreases from mainstream to light-green and dark-green consumers. Regular users of public transport, a valuable proxy for dark-green and light-green consumers in Switzerland, are more likely to buy energy-efficient household appliances than are other consumers.

Hypothesis 4a also finds support from Pehnt and colleagues (2006), who surveyed customers participating in a fuel-cell field test in Germany. Those pioneering customers explicitly stated that low operating costs were very important for them, whereas low initial costs were considered significantly less important. 
The investigations by Deutsch $(2007,2009)$ seem to be the only field experiments that have explored the effect of LCC information provided on the Internet. More precisely, these experiments examined consumers' information search for household appliances on the Website of a shop selling cooling appliances and washing machines. Deutsch analyzed click-stream data to determine the effect of LCC disclosure when mandatory energy-efficiency labels were shown at the same time. Applying multiple regression analysis, he found a $2.5 \%$ reduction of the total energy use due to altered consumption behavior of customers who had at their disposal annual operating cost information on cooling appliances, in comparison with consumers who did not have this information. The reduction in the experiment on washing machines was $0.8 \%$ for both water and energy consumption. The rather tenuous effect in comparison with other empirical evidence can be explained by the constraints of the field experiment. First, the LCC effect was covered in large part by the fact that the mandatory European energy-efficiency label had to be simultaneously disclosed. Second, operating cost information was not automatically displayed in a summary table but rather was separated by text blocks describing the refrigerator models. Therefore, customers could not compare costs without additional cognitive effort.

Diekmann and Meyer (2007) asked about 2,200 individuals in Switzerland whether they preferred a refrigerator for CHF350 (350 Swiss francs) with CHF90 electricity costs per year or a refrigerator for CHF500 that caused CHF50 of electricity costs per year. Of all respondents, 93\% preferred the refrigerator with lower operating costs. The willingness to pay a surplus of CHF150 can be attributed to the effect of LCC information.

Recent empirical evidence from choice experiments with Swiss homeowners (Kaenzig 2008) shows that LCC information clearly increases choice probabilities for ground-source heat pumps, the product with the lowest operating costs figured in the choice set. But the study also shows that low operating costs are not always a sufficient condition to increase the purchase likelihood of eco-innovations with low operating cost. In a two-stage choice experiment, home- owners first had to choose their preferred heating system, seeing initial costs only. In a second choice task, they received a comparative table showing initial and operating costs of the heating systems. As expected, a substantial number of additional respondents (increase of 13\%) chose the system with the lowest operating cost. Not all systems with relatively low operating costs had an increased share in the choice experiment with operating cost disclosure, however. The choices for solar thermal installations, for instance, remained at a similar level, because heat pumps dominate the Swiss heating market and have clearly the lowest operating cost and total LCC. Operating costs of heat pumps were used as a reference for operating costs. This highlights that the effect of LCC on consumer choices depends on the referencing alternatives. The positive effect is not restricted to the heating technology that has the lowest operating costs overall; it also applies to subsets of available or eligible technologies. Heat pumps, for example, are not feasible for every building and building plot; therefore, heating systems with solar thermal installation, for instance, can also benefit from the disclosure of comparative operating cost information. As the alternatives represented in an LCC comparison can be chosen by policy makers or marketers, this is an important finding for determining the presentation of LCC comparisons.

As far as the effect of LCC information on different customer segments is concerned, no significant differences in consumer choices between different segments could be determined. Discriminative effects were not revealed by segmentation on the basis of demographic variables (age, sex, income, education, percentage of employment, number of children), segmentation on the basis of housing characteristics (number of rooms, number of persons per household), or two types of segmentation aimed at distinguishing green, light-green, and other consumers. This is evidence that Hypothesis $4 \mathrm{~b}$ does not hold and that LCC information is effective in promoting ecoinnovation among various consumer segments.

\section{Discussion and Conclusions}

This article makes four important contributions to the literature on consumer decisions 
related to eco-innovation. First, it categorizes products with varying levels of initial and operating costs relative to a reference alternative. Second, it establishes a conceptual model of the cognition of initial and LCC costs, taking into account the moderating effect of the temporal framing of LCC, the type of LCC, consumer-specific cost sensitivity, and reference costs. Third, it provides a review and analysis of empirical evidence of the effects of LCC information on consumer decisions, which was missing in the sustainability marketing literature. Fourth, it introduces LCC information as an instrument for the promotion of eco-innovation that has similar positive effects on all investigated consumer segments.

The confirmation of Hypotheses $1 \mathrm{a}$ and 2 provides elements for answering the research question "How does communication regarding LCC (rather than merely initial costs) change the purchase likelihood of eco-innovations with higher initial costs yet lower operating costs?" The disclosure of LCC information and its discussion triggers long-term thinking in several ways. The disclosure increases the likelihood that LCC are taken into account by consumers and also by stakeholders, who can exert a certain pressure on key actors. Awareness-raising about cognitive biases that accompany intertemporal choices and LCC thinking eases and partly justifies policy interventions aimed at energy efficiency. As far as the presentation of LCC information is concerned, comparative tables are one of the most effective ways to signal operating costs.

Empirical evidence on Hypotheses $1 \mathrm{~b}$ and 3 helps answer the question "Which type and temporal framing of LCC information has the strongest effect on the purchase likelihood of eco-innovations?" When it comes to the format and the temporal framing of LCC information, a comparison of cumulative operating costs of competing products stimulates the choice of energyefficient products more strongly than does a comparison of annual or monthly costs. LCC information presented in table format encourages comparison and increases the choice likelihood of products with lower LCC more strongly than does LCC information for a single product. The reviewed studies do not reveal whether physical or monetary LCC information has a stronger effect on consumer decisions. The question on the most effective type of LCC information cannot be entirely clarified by existing empirical research. Empirical evidence indicates that the European energy-efficiency labeling system might be most effective, as it provides an implicit reference point. Energy-efficiency labeling does not exist for all products that imply high operating costs, however; therefore, explicit LCC computations might evolve for comparisons of, for example, different types of heating equipment.

To answer the third research question, which asks, "Which consumer segments can be influenced by LCC?" there is only one empirical study. The choice experiment from Kaenzig (2008) shows that LCC information has an influence on consumers from all segments. No significant differences between segments could be determined as far as the effect of LCC information is concerned. This is an important finding because it illustrates that LCC is an instrument that can be used to promote eco-innovation across various consumer segments.

A distinction among consumer responses to the four categories of eco-innovation makes sense, with respect to determining the strategy and the choice of the cost profile for the promotion of a specific eco-innovation. This segmentation can be grafted on the segmentation from Wüstenhagen and colleagues (2001) and the framework for sustainability marketing from Belz (2006), which are introduced in the previous section of this article, in which the conceptual model was presented. Three different consumer segments are distinguished with regard to sustainability marketing:

- Dark-green consumers are potential consumers of all types of eco-innovation. Pioneers even buy "tough sell" eco-innovation products, which are more expensive and entail higher operating costs due to, for instance, a special, environmentally sound fuel type. The pioneer market is small, however, and the market beyond this niche must be targeted.

- Light-green consumers would rather not buy tough sell eco-innovations. As do all consumer segments, they buy "no brainers." They also buy eco-innovation products with higher initial costs as well as 
eco-innovations with higher operating costs, when the information is presented so that they can perceive benefits from LCC savings, for instance, or added customer value. Liquidity and sufficient income are, of course, basic prerequisites for consumers' ability to buy eco-innovations with higher initial costs.

- Other (mainstream) consumers who are either not interested in environmental issues or are simply capital-constrained are most likely to adopt no brainers as well as ecoinnovations whose initial costs are shifted to operating costs (e.g., within leasing contracts).

Therefore (1) lowering initial costs and (2) shifting initial costs to operating costs are promising strategies to pave the way from niche to mass market for eco-innovations. On the basis of the conceptual model presented in a previous section of this article and the empirical studies on LCC information, the framework for sustainability marketing can be extended. Two more strategies to overcome the energy-efficiency gap are as follows:

3. lowering perceived initial costs by disclosing comparative LCC (e.g., Internet-based calculators showing cumulative LCC), and

4. increasing the perceived utility of low LCC (e.g., by raising awareness of fuel price risks of conventional alternatives).

The diffusion of eco-innovations beyond niche markets determines global environmental burdens of consumption and the level of dependency on fossil energy. The reciprocal dependency among consumer decisions, marketing, and policy shapes the diffusion of eco-innovations. To put the contribution of this article into context, we note that many other factors determine and influence consumer decisions, such as emotions, advertising, and social context. This article sheds light on a specific aspect and shows that LCC information can be one leverage factor for more long-term thinking. LCC information can influence some consumer decisions regarding eco-innovation, but, more important, it is a prerequisite to initiate and to justify measures for eco-innovation with lower LCC on the policy level and on the corporate level. Transfor- mational sustainability marketing (Dyllick et al. 1997; Belz 2006) is about the active participation of companies in public and political processes to change the existing framework in favor of sustainability. LCC information can be used by companies as well as by policy makers to accelerate the diffusion of eco-innovations.

The findings in this article indicate at least three promising routes for further research. First, it would be interesting to further investigate the influence of the type of LCC information for different categories of eco-innovation. A second avenue for further research is to compare the effectiveness of LCC information in combination with coherent business models. We might expect that the effect of providing LCC information would be higher if, at the same time, customers were offered financial services that helped them to reduce initial costs, which might otherwise be a prohibitive barrier for them. Third, if field experiments confirm our finding that LCC information is indeed an effective way to influence consumer investment decisions regarding eco-innovation, then this raises the important question of appropriate policy instruments to increase the availability of this information for consumers. Examples for policy instruments include eco-labeling schemes whose criteria are explicitly linked to LCC or mandatory LCC disclosure for certain product groups, such as cars or heating systems. More LCC information might soon accelerate the diffusion of eco-innovation by stimulating long-term thinking. The question of how to promote sustainable consumption and production is closely linked to the question of how to promote long-term thinking.

\section{Acknowledgement}

We gratefully acknowledge funding from the Research Fund of the University of St. Gallen. The early stages of development of this article also benefited from seed funding from the Swiss National Science Foundation under its National Research Program 54, Sustainable Development of the Built Environment. The fruitful exchange in the context of the EU-funded research network SCORE (Sustainable Consumption Research Exchange) supported further development of the article. We also thank Thomas Dyllick, Jackie 
Purpura, Thomas Bieker, Matthias Deutsch, Herbert Känzig, Urs Schenker, Mathias Weis, and three anonymous reviewers for their comments.

\section{References}

Akerlof, G. A. 1970. The market for "lemons": Quality uncertainty and the market mechanism. Quarterly Journal of Economics 84(3): 488-500.

Anderson, C. D., and J. D. Claxton. 1982. Barriers to consumer choice of energy efficient products. Journal of Consumer Research 9(2): 163-170.

Belz, F.-M. 2006. Marketing in the 21st century. Business Strategy and the Environment 15(3): 139144.

Bilharz, M. 2007. "Key points" nachhaltigen Konsums. [Key points of sustainable consumption.] Ph.D. thesis, University of St. Gallen, St. Gallen, Switzerland.

Blackwell, R. D., P. W. Miniard, and J. F. Engel. 2005. Consumer behavior, 10th edition, Mason, $\mathrm{OH}$ : South-Western College.

Darby, M., and E. Karni. 1973. Free competition and the optimal amount of fraud. Journal of Law and Economics 16(1): 67-88.

Deutsch, M. 2007. The effect of LCC disclosure on consumer behavior. Ph.D. thesis, University of Maryland.

Deutsch, M. 2010. Life-cycle cost disclosure, consumer behavior, and business implications. Journal of Industrial Ecology. DOI: 10.1111/j.15309290.2009.00201.x.

Diekmann, A., and R. Meyer. 2007. Zeitpräferenzen und Energiesparen. Ergebnisse aus dem Schweizer Umweltsurvey. [Time preferences and energy saving. Findings from the Swiss Environment Survey.] Presentation at the Energiewirtschaftliche Grundlagen Workshop, 12 November, Swiss Federal Office of Energy, Bern, Switzerland.

Dyllick, T., F.-M. Belz, and U. Schneidewind. 1997. Ökologie und Wettbewerbsfähigkeit. [Ecology and competitiveness.] Munich, Germany: Carl Hanser Verlag.

Enkvist, P.-A., T. Nauclér, and J. Rosander. 2007. A cost curve for greenhouse gas reduction. McKinsey Quarterly (1): 35-45.

Esch, F.-R., A. Hermann, and H. Sattler. 2007. Marketing: Eine managementorientierte Einführung. [Marketing. A management oriented introduction.] Munich, Germany: Vahlen.

Frederick, S., G. Loewenstein, and T. O'Donoghue. 2002. Time discounting and time preference: A critical review. Journal of Economic Literature 40(2): 351-401.

Gourville, J. T. 1998. Pennies-a-day: The effect of tem- poral reframing on transaction evaluation. Journal of Consumer Research 24(4): 395-408.

Hunkeler, D., K. Lichtenvort, and G. Rebitzer. 2008. Environmental life cycle costing. Boca Raton, FL: CRC Press.

Hutton, R. B., and W. L. Wilkie. 1980. Life cycle cost: A new form of consumer information. Journal of Consumer Research 6(4): 349-360.

Jackson, T. 2005. Live better by consuming less? Is there a "double dividend" in sustainable consumption? Journal of Industrial Ecology 9(1-2): 19-36.

Jaffe, A. B., and R. N. Stavins. 1994. The energy efficiency gap: What does it mean? Energy Policy 22(10): 804-810.

Kaas, K. P. 1992. Marketing für umweltfreundliche Produkte: Ein Ausweg aus den Dilemmata der Umweltpolitik? [Marketing for environmentally sound products: A way out of the dilemma of environmental policy.] Die Betriebswirtschaft 52(4): 473-488.

Kaenzig, J. 2008. The effect of life cycle cost information on consumer investment decision: Empirical evidence. Paper presented at the International Workshop on Empirical Economics, 29-30 September, CEPE-ETH, Zürich, Switzerland.

Kaenzig, J., and O. Jolliet. 2007. Prioritizing sustainable consumption patterns: Key decisions and environmental gains. International Journal of Innovation and Sustainable Development 2(2): 140-154.

Kaenzig, J., and R. Wüstenhagen. 2008. Understanding the green energy consumer. Marketing Research St. Gallen 4: 12-16.

Kahneman, D. 2003. Maps of bounded rationality: Psychology for behavioral economics. American Economic Review 993(5): 1449-1475.

Kahneman, D., and A. Tversky. 1979. Prospect theory: An analysis of decisions under risk. Econometrica 47(2): 263-291.

Kempton, W., J. M. Darley, and P. C. Stern. 1992. Psychological research for the new energy problems: Strategies and opportunities. American Psychologist 47(10): 1213-1223.

Kirchgeorg, M., and G. Greven. 2008. Motivallianzen als Treiber des nachhaltigen Konsums. [Motif alliances as drivers of sustainable consumption.] Marketing Review St. Gallen (4): 50-54.

Kleinhückelkotten, S. 2005. Suffizienz und Lebensstile: Ansätze für eine milieuorientierte Nachhaltigkeitskommunikation. [Sufficiency and lifestyles: Approaches for a milieu-oriented sustainability communication.] Berlin: Berliner WissenschaftsVerlag.

Lancaster, K. 1966. A new approach to consumer theory. Journal of Political Economy 74(2): 132157. 
Liebermann, Y., and M. Ungar. 1997. Life cycle cost: An individual consumer's perspective. Managerial and Decision Economics 18(3): 227-234.

Liebermann, Y., and M. Ungar. 2002. Efficiency of consumer intertemporal choice under life cycle cost conditions. Journal of Economic Psychology 23(6): 729-748.

Loewenstein, G., and D. Prelec. 1992. Anomalies in intertemporal choice: Evidence and an interpretation. Quarterly Journal of Economics 107(2): 573 597.

Louviere, J., D. A. Hensher, and J. D. Swait. 2000. Stated choice methods: Analysis and applications. Cambridge, UK: Cambridge University Press.

Lund, R. T. 1978. Life cycle costing: A business and societal instrument. Management Review 67(4): 12 23.

Lynch, J. G., and W. Wood. 2006. Special issue editors' statement: Helping consumers help themselves. Journal of Public Policy ES Marketing 25(1): 1-7.

McNeill, D. L., and W. L. Wilkie. 1979. Public policy and consumer information: Impact of the new energy labels. Journal of Consumer Research 6(1): $1-11$.

Meffert, H., and M. Bruhn. 1996. Das Umweltbewusstsein von Konsumenten. [Environmental awareness of consumers.] Die Betriebswirtschaft 56(5): 631-648.

Nelson, P. 1970. Information and consumer behavior. Journal of Political Economy 78(2): 311-329.

Pehnt, M., M. Cames, C. Fischer, B. Praetorius, L. Schneider, K. Schumacher, and J.-P. Voss. 2006. Micro cogeneration: Towards decentralized energy systems. Berlin: Springer.

Rebitzer, G. 2005. Enhancing the application efficiency of life cycle assessment for industrial uses. Ph.D. thesis, EPFL, Lausanne, Switzerland.

Rennings, K. 2000. Redefining innovation: Ecoinnovation research and the contribution from ecological economics. Ecological Economics 32(2): 319-332.

Revelt, D., and K. Train. 1998. Mixed logit with repeated choices: Households' choices of appliance efficiency level. Review of Economics and Statistics 80(4): 647-657.

Sammer, K., and R. Wüstenhagen. 2006. The influence of eco-labeling on consumer behavior: Results of a discrete choice analysis. Business Strategy and the Environment 15(3): 185-199.

Samuelson, W., and R. Zeckhauser. 1988. Status bias in decision making. Journal of Risk and Uncertainty 1(1): 7-59.

Spence, M. 1973. Job market signaling. Quarterly Journal of Economics 87(3): 355-374.

Stiglitz, J. 1975. The theory of "screening," education, and the distribution of income. American Economic Review 5(3): 283-300.

Thaler, R. H. 1980. Towards a positive theory of consumer choice. Journal of Economic Behavior and Organization 1(1): 39-60.

Thaler, R. H. 1981. Some empirical evidence on dynamic inconsistency. Economic Letters 8(3): 201207.

Train, K. 1985. Discount rates in consumers' energyrelated decisions: A review of the literature. Energy 10(12): 1243-1253.

Tukker, A., and B. Jansen. 2006. Environmental impacts of products: A detailed review of studies. Journal of Industrial Ecology 10(3): 159-182.

Tversky, A., and D. Kahneman. 1974. Judgment under uncertainty: Heuristics and biases. Science 185(4157): 1124-1131.

Tversky, A., and D. Kahneman. 1981. The framing of decisions and the psychology of choice. Science 211(4481): 453-458.

Villiger, A., R. Wüstenhagen, and A. Meyer. 2000. Jenseits der Öko-Nische. [Beyond the ecological niche.] Basel, Switzerland: Birkhäuser.

Wilson, C., and H. Dowlatabadi. 2007. Models of decision making and residential energy use. Annual Review of Environment and Resources 32: 169-203.

Wüstenhagen, R., and K. Sammer. 2007. Wirksamkeit umweltpolitischer Anreize zum Kauf energieeffizienter Fahrzeuge: eine empirische Analyse Schweizer Automobilkunden. [The effectiveness of policy incentives for the purchase of energy-efficient cars: an empirical analysis of Swiss car purchasers.] Zeitschrift für angewandte Umweltforschung (Journal of Environmental Research) 18(1): 61-78.

Wüstenhagen, R., A. Villiger, and A. Meyer. 2001. Bio-Lebensmittel jenseits der Öko-Nische. [Organic food products beyond the ecological niche. In Sustainable consumption - dialog research and practice.] In Nachhaltiger Konsum-Forschung und Praxis im Dialog, edited by U. Schrader and U. Hansen. Frankfurt, Germany: Campus Verlag.

\section{About the Authors}

Josef Kaenzig was a research associate at the University of St. Gallen in St. Gallen, Switzerland, at the time the article was written. He is currently a consultant in the areas of sustainable consumption and production for the Federal Office for the Environment, Berne, Switzerland. Rolf Wuestenhagen is an associate professor and holds the Good Energies Chair for Management of Renewable Energies at the University of St. Gallen. 